\title{
Frequently used Anisotropic Yield Criteria for Sheet Metal Applications: A Review
}

\author{
S. P. Sundar Singh Sivam ${ }^{1 *}$, V. G Uma Sekar', K. Saravanan'², S. RajendraKumar', \\ P. Karthikeyan' ${ }^{1}$ and K. Sathiya Moorthy' \\ 'Department of Mechanical Engineering, SRM University, Kattankulathur, Chennai - 603203, Tamil Nadu, India; \\ sundar.sp@ktr.srmuniv.ac.in, umasekar.g@ktr.srmuniv.ac.in, rajendrakumar.s@ktr.srmuniv.ac.in, \\ karthikeyan.pa@ktr.srmuniv.ac.in, sathiya.k@ktr.srmuniv.ac.in \\ 2Department of Mechatronics Engineering, SRM University, Kattankulathur, Chennai - 603203, Tamil Nadu, India; \\ saravanan.kn@ktr.srmuniv.ac.in
}

\begin{abstract}
Objectives: To study the yield behavior and plastic flow of an anisotropic sheet metal during forming operations, various mathematical formulations of the plastic state of the sheet metals have been proposed, known as yield functions. Different yield functions pertain to different criteria and have different characteristics. Methods/Statistical Analysis: There are several yield criteria proposed for the study of yield behaviors of sheet metals. This paper aims at reviewing the most frequently and commonly employed for the purpose yield criteria i.e. Hill 1948, Barlat 1989, Hill 1990 and BBC 2000. The study is focused on discussing the form of each criterion, their implementation details and comparing their predictive accuracies. Findings: The methods followed to obtain the yield surface diagram have been reviewed and discussed. Application/Improvement: Inference has been drawn based upon the agreement between theoretical and experimental value for a particular case.
\end{abstract}

Keywords: Accuracy Index, Anisotropic Coefficients, Yield Criteria

\section{Introduction}

The metal forming operation accepts the yielding of the metals once strained. Yielding is characterized by the plastic flow of the materials once strained ${ }^{1}$. The yield purposes just in case of uniaxial tension are often simply determined from the stress strain graph, however in case of multiaxial stresses it gets sophisticated. A Connection between the principal stresses is required identify the situation below that plastic metal flow iterate.

Such a courting is sometimes outlined within a kind of an implicit perform 1 : F of three Principal Stresses and yield Stress obtained from mechanical test. The term is often represented as a surface in an exceedingly 3-D area wherever the points lying on the surface $\mathrm{F}$ equals to Zero refer to the plastic condition of the material, a points lying inside the surface $\mathrm{F}$ lesser than Zero refer in the direction of the elastic condition and the points outside the surface F Greater than Zero have no significance. In the situation that of plane stress the yield plane minimized to a curve in the plane of the principal stresses $\sigma 1$ and $\sigma 2^{1}$.

Since its origination, there are many several yield criteria projected, the fore most ordinarily used ${ }^{1}$ pre stated Yield function. The initiate event of anisotropic yield was Hill $\underline{2,3}$.

${ }^{*}$ Author for correspondence 
He proposed in 1948 a quadratic formulation. He improved his models in Hill $1990^{1}$ and Hill $1993^{1}$. Barlat ${ }^{1,4-6}$ outlined many extensions of the isotropic yield criterion projected by Hosford in 1951, employing a processing straight transformation of the Cauchy stress. The BBC (Banabic - Balan - Comsa) $)^{1,6,7}$ models are unit developments of the Hill $1948^{2,6}$ and Barlat 1989, $\frac{1,4,8,8}{1}$ yield criteria.

\subsection{Need for Study}

The determination of plastic flow state for a sheet metal is very important to study its yield characteristics. In case of uniaxial stress, the point of yield be conveniently obtained from the stress strain curve, but when multiaxial stresses are present, it becomes more complex and requires an advance flow equation. This complexity is addressed by the anisotropic yield functions. Also, the experiments used to obtain yield loci may be expensive and time taking; in such case these yield functions prove to be very effective. The yield criteria also help in determining planar distribution of yield stresses and anisotropic coefficients, which gives a good estimate of these mechanical parameters without having to through the pain of experimental determination. Different yield criteria have different accuracy and advantages. Some are highly accurate and flexible, while some are known for their simplicity and ease to manipulate. This review paper aims at doing comparative study of most frequently used yield functions and draw inferences.

\section{Yield Criteria Description}

\subsection{Hill 1948}

During 1948 Yield Hill $\stackrel{1,2}{\circ}$ projected an anisotropic yield for forming of sheet metals. The yield is articulated by a quadratic perform of the subsequent type $e^{1,2}$ :

$$
\begin{aligned}
& 2 \mathrm{f}\left(\sigma_{\mathrm{xy}}\right) \equiv \mathrm{F}\left(\sigma_{\mathrm{bb}}-\sigma_{\mathrm{cc}}\right)^{2}+\mathrm{G}\left(\sigma_{\mathrm{cc}}-\sigma_{\mathrm{aa}}\right)^{2}+\mathrm{H}\left(\sigma_{\mathrm{aa}}-\sigma_{\mathrm{bb}}\right)^{2}+ \\
& 2 \mathrm{~L}\left(\sigma_{\mathrm{bc}}\right)^{2}+2 \mathrm{M}\left(\sigma_{\mathrm{ca}}\right)^{2}+2 \mathrm{~N}\left(\sigma_{\mathrm{ab}}\right)^{2}=1 \frac{1,2}{}
\end{aligned}
$$

Here $\mathrm{f}$ is the forming of sheet metal yields performs F, G, H, L, M and N is anisotropy state of the forming of sheet material.

while Numerical of forming procedure, the rolling direction of $0^{\circ}, 45^{\circ}, 90^{\circ}$ is the anisotropy and the principal axes are indicated as: $\mathrm{X}=\sigma_{0}, \mathrm{Y}=\sigma_{90}$, are the direction of yield stresses. Assumptive plane stress conditions, the equation can be subsequent as:

$$
\begin{aligned}
& \sigma_{1}^{2}-\left[\left(2 r_{0} /\left(1+r_{0}\right)\right) \sigma_{1} \sigma_{2}\right]+\left[\left(r_{0}\left(1+r_{90}\right)\right) /\left(r_{90}\left(1+r_{0}\right)\right)\right] \\
& \sigma_{2}^{2}=\sigma_{0}^{2}
\end{aligned}
$$

This equation represents the family of ellipses depending upon the values of $\mathrm{r}_{0}$ and $\mathrm{r} \mathrm{9}_{0}$.

Discussion of Hill 1948 function is well presented in ${ }^{9,10}$.

The hill'48 equation predicts the disparity of uniaxial stress with relation to angle $\theta$ as:

$$
\begin{aligned}
& \mathrm{Y}_{\theta}=\left[(\mathrm{Y}(\mathrm{h})) /\left(\mathrm{G} \cos ^{2} \theta+\mathrm{F} \sin ^{2} \theta+\mathrm{H}\left(\cos ^{2} \theta-\sin ^{2} \theta\right)+\right.\right. \\
& \left.\left.2 \mathrm{~N} \sin ^{2} \theta \cos ^{2} \theta\right)^{(1 / 2)}\right]
\end{aligned}
$$

The actualization for the uniaxial anisotropy to declare by the Hill' 48 yield criterion is acquired as:

$$
\begin{aligned}
& r_{\theta}=\left[\left(G \cos ^{4} \theta+F \sin ^{4} \theta+\mathrm{H}^{2} \cos ^{2} 2 \theta+(1 / 2)\left(\mathrm{N} \sin ^{2} 2 \theta\right)\right) /\right. \\
& \left.\left(\mathrm{G} \cos ^{2} \theta+\mathrm{F} \sin ^{2} \theta\right)\right]-1
\end{aligned}
$$

\subsection{Hill 1990 Criterion}

Hill formulated the following yield criterion in $1990^{3,11}$ for general coordinate system:

$$
\begin{aligned}
& \phi=\left|\sigma_{\mathrm{aa}}+\sigma_{\mathrm{bb}}\right|^{\mathrm{m}}+\left(\sigma_{\mathrm{b}}^{\mathrm{m}} / \tau^{\mathrm{m}}\right)\left|\left(\sigma_{\mathrm{aa}}-\sigma_{\mathrm{bb}}\right)^{2}+4\left(\sigma_{\mathrm{ab}}\right)^{2}\right|^{(\mathrm{m} / 2)}+ \\
& \left|\left(\sigma_{\mathrm{aa}}\right)^{2}+\left(\sigma_{\mathrm{bb}}\right)^{2}+2\left(\sigma_{\mathrm{ab}}\right)^{2}\right|^{(\mathrm{m} / 2)-1} \\
& \left\{-2 \mathrm{a}\left(\sigma_{\mathrm{aa}}{ }^{2}-\sigma_{\mathrm{bb}}{ }^{2}\right)+\mathrm{b}\left(\sigma_{\mathrm{aa}}-\sigma_{\mathrm{bb}}\right)^{2}\right\}=\left(2 \sigma_{\mathrm{b}}\right)^{\mathrm{m}}
\end{aligned}
$$

The yield stress $\sigma_{\mathrm{b}}$ in equibiaxial tension, the yield stress $\tau$ in pure shear formation $(\sigma 1=-\sigma 2)$, a $\&$ b are constants.

The $\mathrm{m}$ is obtained to solve by the subsequent relation: $\left(2 * \sigma_{\mathrm{b}} / \sigma_{45}\right) \mathrm{m}=2 *\left(1+\mathrm{r}_{45}\right)$

The terms a \& b is resolute from the below terms:

$$
\begin{aligned}
& \mathrm{a}=(1 / 4)\left|\left(2 \sigma_{\mathrm{b}} / \sigma_{90}\right)^{\mathrm{m}}-\left(2 \sigma_{\mathrm{b}} / \sigma_{0}\right)^{\mathrm{m}}\right| ; \\
& \mathrm{b}=(1 / 2)\left[\left(2 \sigma_{\mathrm{b}} / \sigma_{0}\right)^{\mathrm{m}}+\left(2 \sigma_{\mathrm{b}} / \sigma_{90}\right)^{\mathrm{m}}\right]-\left(2 \sigma_{\mathrm{b}} / \sigma_{45}\right)^{\mathrm{m}}
\end{aligned}
$$

The ratio $\sigma_{\mathrm{b}} / \tau$ perhaps in addition articulated as a purpose of coefficient $r_{45}$ :

$$
\left(\sigma_{b} / \tau\right) m=1+2 \cdot r_{45}
$$

The uniaxial yield stress variation is predicted when:

$$
\mathrm{Y}_{\theta}=\left[\left(4 \sigma_{\mathrm{b}}\right) /\left(1+\left(\sigma_{\mathrm{b}} / \tau\right)^{\mathrm{m}}-2 \mathrm{a} \cos 2 \theta+\mathrm{b} \cos ^{2} 2 \theta\right)^{(1 / \mathrm{m})}\right]
$$

The uniaxial anisotropy is predicted as:

$$
\begin{aligned}
& \mathrm{r}_{\theta}=\left[\left(\left(\sigma_{\mathrm{b}} / \tau\right)^{\mathrm{m}}-1+\left(2 \mathrm{~b} \cos ^{2} 2 \theta / \mathrm{m}\right)\right) /(2-2 \mathrm{a} \cos 2 \theta+\right. \\
& \left.\left.\left((\mathrm{m}-2) \mathrm{b} \cos ^{2} 2 \theta / \mathrm{m}\right)\right)\right]-1
\end{aligned}
$$


An argument of the process method of the parameters in Hill's 1990 yield crietrieon is conferred in $\underline{3,11}$

\subsection{Barlat 1989}

In the specific case of thin sheets under plane stress conditions, Barlat $1989 \stackrel{1,4,5,11}{=}$ yield criterion has the following formulation:

$$
\begin{aligned}
& \bar{\sigma}=\left[\mathrm{a}\left|\hat{\mathrm{K}}_{\mathrm{a}}+\hat{\mathrm{K}}_{\mathrm{b}}\right|^{\mathrm{m}}+\mathrm{a}\left|\hat{\mathrm{K}}_{\mathrm{a}}-\hat{\mathrm{K}}_{\mathrm{b}}\right|^{\mathrm{m}}+(1-\mathrm{a})\left|2 \hat{\mathrm{K}}_{\mathrm{b}}\right|^{\mathrm{m}}\right]^{(1 / \mathrm{m})} \\
& \hat{\mathrm{K}}_{1}=\left(\hat{\sigma}_{\mathrm{aa}}+\mathrm{h} \hat{\sigma}_{\mathrm{bb}}\right) / 2 ; \hat{\mathrm{K}}_{2}=\operatorname{sqrt}\left(\hat{\mathrm{K}}_{1}^{2}+\mathrm{p}^{2} \hat{\sigma}_{12}\right) \\
& \mathrm{a}=2-\mathrm{c}=\left[\left(2\left(\sigma_{\mathrm{e}} \tau_{\mathrm{s} 2}\right)^{\mathrm{M}}-2\left(1+\left(\sigma_{\mathrm{e}} / \sigma_{90}\right)\right)^{\mathrm{M}}\right) /\left(1+\left(\sigma_{\mathrm{e}} / \sigma_{90}\right)\right.\right. \\
& \left.\left.\mathrm{M}-\left(1+\left(\sigma_{\mathrm{e}} / \sigma_{90}\right)\right)^{\mathrm{M}}\right)\right] \\
& \mathrm{h}=\left(\sigma_{\mathrm{e}} / \sigma_{90}\right) \\
& \mathrm{p}=\sigma_{\mathrm{e} /} \tau_{\mathrm{sa}}\left(2 /\left(2 \mathrm{a}+2^{\mathrm{M}} \mathrm{c}\right)\right)^{1 / \mathrm{M}}
\end{aligned}
$$

$\mathrm{p}$ and $\mathrm{h}$ are material range familiar with depict the material anisotropic yield surfaces, 'a' is a material constant that takes values in the $[0,1]$ range. The exponent ' $m$ ' is an integer value.

$\mathrm{m}=6$ and 8 for BCC and FCC alloys.

To identify the, $\mathrm{h}$ and $\mathrm{p}$ material model, the experimental standards of the anisotropy coefficients.

The description and application of Barlat 1989 criterion is well depicted in ${ }^{9}$

The expression for uniaxial yield stress was given by barlat is as:

$$
\mathrm{Y}_{\theta}=\left[\left(\mathrm{Y}_{0}\right) /\left(\mathrm{a}\left(\mathrm{F}_{\mathrm{a}}+\mathrm{F}_{\mathrm{b}}\right)^{\mathrm{M}}+\mathrm{a}\left(\mathrm{F}_{\mathrm{a}}-\mathrm{F}_{\mathrm{b}}\right)^{\mathrm{M}}+(1-\mathrm{a})\left(2 \mathrm{~F}_{\mathrm{b}}\right)^{\mathrm{M}}\right)^{1 / \mathrm{M}}\right]
$$

where

$\mathrm{F}_{\mathrm{a}}=\mathrm{h} \sin ^{2} \theta+\cos ^{2} \theta(1 / 2)$

$\mathrm{F}_{\mathrm{b}}=\left[\left(\mathrm{h} \sin ^{2} \theta-\cos ^{2} \theta / 2\right)+\mathrm{p}^{2} \cos ^{2} \theta \sin ^{2} \theta\right]$

The function $\mathrm{F}_{\theta}$ is obtained as:

$\mathrm{F}_{\theta}=\left[\mathrm{a}\left(\mathrm{F}_{\mathrm{a}}+\mathrm{F}_{\mathrm{b}}\right)^{\mathrm{M}}+\mathrm{a}\left(\mathrm{F}_{\mathrm{a}}-\mathrm{F}_{\mathrm{b}}\right)^{\mathrm{M}}+(1-\mathrm{a})\left(2 \mathrm{~F}_{\mathrm{b}}\right)^{\mathrm{M}}\right]^{1 / \mathrm{M}}$

\subsection{BBC 2000 Criterion}

During 2000, the BBC (Banabic - Balan - Comsa) 2000 1,6,7 yield function was projected by Barlat in 1989. The equivalents yield:

$$
\bar{\sigma}=\left[\mathrm{a}(\Gamma+\Psi)^{2 \mathrm{k}}+\mathrm{a}(\Gamma-\Psi)^{2 \mathrm{k}}+(1-\mathrm{a})(2 \Psi)^{2 \mathrm{k}}\right]^{(1 / 2 \mathrm{k})}
$$

the functions $\Gamma, \Psi$, and $\Lambda$ are definite as:

$$
\begin{aligned}
& \Gamma=\left(\hat{\sigma}_{11}+\mathrm{M} \hat{\sigma}_{22}\right) / 2 \\
& \Psi=\operatorname{sqrt}\left[\left(\left(\mathrm{N} \hat{\sigma}_{11}-\mathrm{P} \hat{\sigma}_{22}\right)^{2} / 4\right)+\left(\mathrm{Q} \hat{\sigma}_{12}\right)^{2}\right] \\
& \Lambda=\operatorname{sqrt}\left[\left(\left(\hat{\mathrm{O}}_{11}-\mathrm{S} \hat{\sigma}_{22}\right)^{2} / 4\right)+\left(\mathrm{T} \hat{\sigma}_{12}\right)^{2}\right]
\end{aligned}
$$

The coefficients a and $\mathrm{k}$ are material factors. The other sheet material functions like $\mathrm{M}, \mathrm{N}, \mathrm{P}, \mathrm{Q}, \mathrm{R}, \mathrm{S}$ and $\mathrm{T}$. To calculated using the following experimental data: $r_{0}, r_{45}$, $\mathrm{r}_{90}, \mathrm{r}_{\mathrm{b}}, \sigma_{0}, \sigma_{90}, \sigma_{45}, \sigma_{\mathrm{b}}$.

The description and application of this criterion can be found in ${ }^{12}$.

The rolling path of different angles for uniaxial yield sheet material is given as:

$$
\begin{aligned}
& \sigma_{\phi}=\left[\mathrm{Y} /\left(\mathrm{a}\left(\mathrm{bA}_{\phi}+\mathrm{cB}_{\phi}\right)^{2 \mathrm{k}}+\mathrm{a}\left(\mathrm{bA}_{\phi}-\mathrm{cB}_{\phi}\right)^{2 \mathrm{k}}+(1-\mathrm{a})\right.\right. \\
& \left.\left.(2 \mathrm{cB})^{2 \mathrm{k}}\right)^{(1 / 2 \mathrm{k})}\right] \\
& \mathrm{A}_{\phi}=\mathrm{M} \cos ^{2} \phi+\mathrm{N} \sin ^{2} \phi \\
& \mathrm{B}_{\phi}=\operatorname{sqrt}\left[\left(\mathrm{P} \cos ^{2} \phi+\mathrm{N} \sin ^{2} \phi\right)^{2}+\mathrm{R} \sin ^{2} \phi \cos ^{2} \phi\right]
\end{aligned}
$$

The plastic anisotropy coefficient is given as:

$$
\begin{aligned}
& \mathrm{r}_{\phi}=\left[\left(\mathrm{Y} / \sigma_{\phi}\right) /\left(\partial \Phi / \partial \Gamma\left(\partial \Gamma / \partial \sigma_{11}+\partial \Gamma / \partial \sigma_{22}\right)+\partial \Phi / \partial \Psi\left(\partial \sigma_{11}\right.\right.\right. \\
& \left.\left.\left.+\partial \Psi / \partial \sigma_{22}\right)\right)\right]-1 \\
& \partial \Phi \backslash \partial \Gamma=\mathrm{b}\left(\sigma_{\phi} / \mathrm{Y}\right)^{2 \mathrm{k}-1}\left[\mathrm{a}\left(\mathrm{bA}_{\phi}+\mathrm{cB}_{\phi}\right)^{2 \mathrm{k}-1}+\mathrm{a}\left(\mathrm{bA}_{\phi}-\mathrm{cB}_{\phi}\right)^{2 \mathrm{k}-1}\right] \\
& \partial \Phi \backslash \partial \Psi=\mathrm{c}\left(\sigma_{\phi} / \mathrm{Y}\right)^{2 \mathrm{k}-1}\left[\mathrm{a}\left(\mathrm{bA}_{\phi}+\mathrm{cB}_{\phi}\right)^{2 \mathrm{k}-1}+\mathrm{a}\left(\mathrm{bA}_{\phi}-\mathrm{cB}_{\phi}\right)^{2 \mathrm{k}-1}\right. \\
& \left.\left.+2(1-\mathrm{a})(2 \mathrm{cB})_{\phi}\right)^{2 \mathrm{k}-1}\right] \\
& \partial \Gamma / \partial \sigma_{11}=\mathrm{M}, \partial \Gamma / \partial \sigma_{22}=\mathrm{N} \\
& \partial \Psi / \partial \sigma_{11}=\left(\mathrm{P} / \mathrm{B}_{\phi}\right)\left(\mathrm{P}^{2} \cos ^{2} \phi+\mathrm{Q} \sin ^{2} \phi\right) \\
& \partial \Psi / \partial \sigma_{22}=\left(\mathrm{Q} / \mathrm{B}_{\phi}\right)\left(\mathrm{P}_{\cos ^{2} \phi} \phi \operatorname{Qin}^{2} \phi\right)
\end{aligned}
$$

\subsection{Tools Used}

Universal Testing Machine for measuring yield stresses and r-values. Numerical Simulation Packages like ABAQUS, AUTOFORM, and LS-DYNA $\stackrel{1,8}{\text {. }}$

\subsubsection{Procedure}

The yield loci of a particular sheet metal can be determined both, experimentally and mathematically. For experimental determination a cross tensile specimen can be used ${ }^{8}$. As described by ${ }^{12}$, a CNC stretch-drawing machine can be used to load the specimen in biaxial directions. In one of his work ${ }^{12}$, author describes, Biaxial tensile bend tests were dispensed on circulate sheet specimens of Aluminium, $1.2 \mathrm{~mm}$ of samples employing drawing ability ${ }^{17}$. The start of plastic yielding was monitored by temperature measurements. However, throughout plastic flow, the temperature rose powerfully and also the values of principal strains were recorded. The plastic flow can even be detected through DIC techniques ${ }^{1}$. For numerical simulation, experimental values of anisotropic coefficients $\frac{13}{}$ and yield stresses are required along different directions. They can be obtained using a UTM following ASTM E8 or ASTM E517 ${ }^{14}$ standard. For 
calculating r-values the specimens are needed to be cut out at particular angle from the rolling path and strained longitudinally. The recommended value of strain is $20 \%$ of the specimen length 1 . Once these mechanical parameters are obtained, they can be fed into the finite element code in software's like ABAQUS, LS-DYNA, and AUTOFORM ${ }^{1}$ etc. to obtain the respective YSDs $\frac{2,8,20-22}{\text {. }}$

\subsubsection{Accuracy Index}

Consecutively to possess an inclusive analysis tool, the accuracy index defined as follows $s^{1,15-17}$.

$$
\beta=\phi+\delta+\gamma[\%]
$$

1. $\varphi$ is an accuracy index with respect to the forecast of the yield locus form within the plane of the principal stresses.

2. $\delta$ is that the accuracy index allied to the prediction of the planar distribution of the uniaxial yield stress.

3. $\gamma$ is that the accuracy index linked to the forecast of the planar distribution of the uniaxial coefficient of plastic anisotropy.

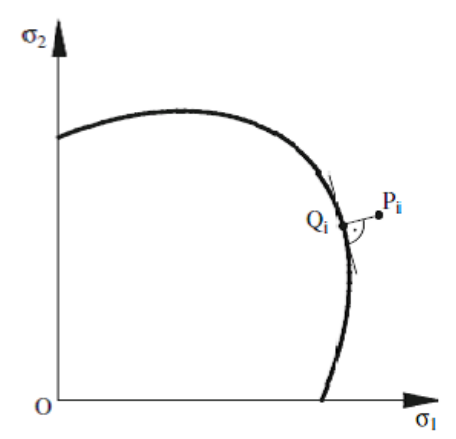

Figure 1. The yield locus expected by an $\mathrm{YC}^{1}$.

$\phi$ is calculated by means of the usage of the formula $\phi=\operatorname{sqrt}\left[\Sigma\left(\mathrm{d}^{2}\left(\mathrm{P}_{\mathrm{i}}, \mathrm{Q}_{\mathrm{i}}\right)\right)\right] / \mathrm{Y}^{\star} 100[\%]$

$\delta$ is calculated by means of the usage of the formula

$\left.\left.\delta=\operatorname{sqrt}\left[\Sigma\left(\sigma_{\theta \theta_{i}}^{\mathrm{e}}-\sigma_{\theta_{\mathrm{i}}}^{\mathrm{t}}\right) \sigma_{\theta_{\mathrm{i}}}\right]^{\mathrm{e}}\right)\right]^{*} 100[\%]$

$\gamma$ is calculated by means of the usage of the formula

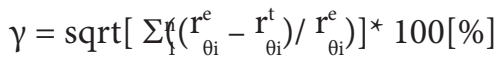

\section{Results, Discussion and Comparison of Yield Criteria}

The comparison between the chosen yield criteria is based upon their effectiveness in predicting the yield loci and variation of yield stresses further as anisotropic coefficients with relevance the rolling direction. The aluminum AA3103 material has been chosen.

The Figures 1-4, show the yield surface diagrams, planar allocation of uniaxial yield stresses and anisotropic coefficients as expected by the chosen yield criteria in conjunction with the developmental data ${ }^{1,6,7}$. In case of yield loci, it is evident that Banabic - Balan - Comsa 2000 and Hill 1990 yield criterian have greater accurateness and predominantly within the line in the biaxial tension. Again in the next diagram, Banabic - Balan - Comsa and 1990 models have improved. Since Hill 1948 and Barlat 1989 models use only the uniaxial stress equivalent to all three rolling direction $\frac{1}{1}$, their predictions are in poor agreement with the developmental result. But in case of the planar distribution of anisotropic coefficients, Banabic - Balan - Comsa 2000, Hill 1948 and Barlat 1989 have better action, why because Hill 1990 uses only the function equivalent to the diagonal path in its recognition procedure ${ }^{1}$. Thus it is safe to deduce that greater predictive accuracy will be obtained for the yield criterion which uses parameters which are based on both uniaxial and biaxial tensile test. For greater flexibility and accuracy, a yield criterion should include a minimum of seven parameters, including yield stresses and anisotropic coefficients equivalent to three planar directions 0,45 and $90 \mathrm{deg}^{1}$.

For a comprehensive evaluation of comparison results, the global accuracy index ${ }^{8,18-22 .}$ Mentioned earlier should be used. The information ${ }^{1}$ for quality index for numerous yield criteria is shown in Figure 2. The foremost effective overall efficiency deals to the rock bottom result of the comprehensive index $\beta$. The Table.1 depicts that Banabic - Balan - Comsa 2000 has higher performances as compare to the supplementary function.

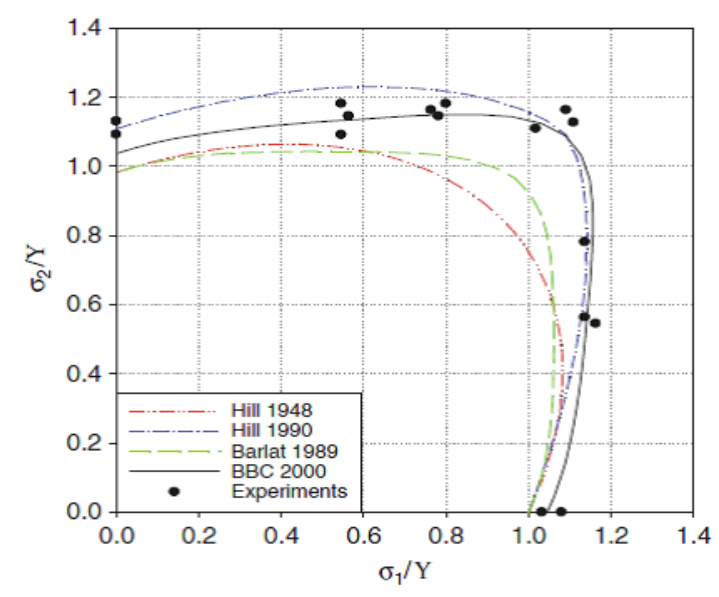

Figure 2. Yield loci expected by means of the Hill $1948^{1}$. 


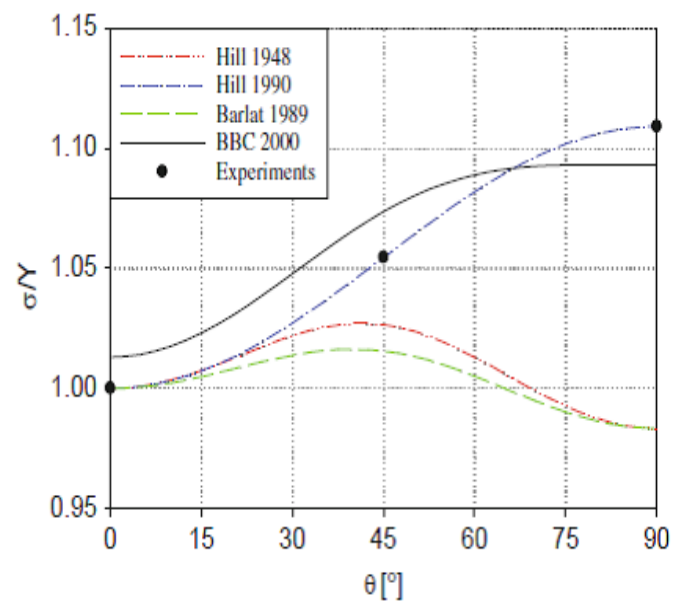

Figure 3. Uniaxial yield stresses expected by means of the Hill $1948^{1}$.

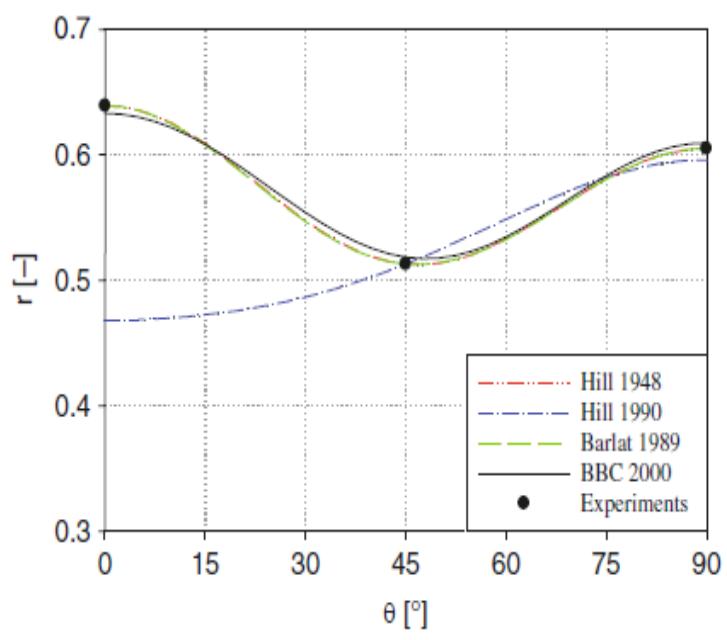

Figure 4. Anisotropy coefficients expected by means of the Hill 1948 ${ }^{1}$.

Table 1. Forming Quality index for dissimilar yield criteria ${ }^{1}$

\begin{tabular}{|l|c|c|c|c|c|}
\hline Material $^{1}$ & $\begin{array}{c}\text { Quality } \\
\text { Index }^{1}\end{array}$ & $\begin{array}{c}\text { Hill } \\
\mathbf{1 9 4 8}^{\underline{1}}\end{array}$ & $\begin{array}{c}\text { Hill } \\
\mathbf{1 9 9 0}^{\underline{1}}\end{array}$ & $\begin{array}{c}\text { Barlat } \\
\mathbf{1 9 8 9}^{\underline{1}}\end{array}$ & $\begin{array}{c}\text { BBC } \\
\mathbf{2 0 0 0}^{\underline{1}}\end{array}$ \\
\hline \multirow{4}{*}{ AA103-0 } & $\phi[\%]$ & 42.64 & 18.8 & 30.64 & 13.41 \\
\cline { 2 - 6 } & $\delta[\%]$ & 11.65 & 0 & 11.92 & 2.64 \\
\cline { 2 - 6 } & $\Gamma[\%]$ & 0 & 36.05 & 0 & 1.60 \\
\cline { 2 - 6 } & $\beta[\%]$ & 54.29 & 56.03 & 42.56 & 17.65 \\
\hline
\end{tabular}

\section{Conclusion}

The Forming quality index of different yield criteria and their comparison with the experimental data suggests that the criteria with more no. of parameters are more accurate, although the determination of more no. of parameters could be expensive and time taking. Ultimately it's a tradeoff between a no. of factors, namely accuracy, computational efficiency, and flexibility of yield criterion, no. of mechanical parameters required, experimental difficulties, user-friendliness and acceptance. While hill 1948 criterion stands out due to its simplicity, user-friendliness and requirement of just four mechanical parameters, BBC 2000 offers far greater accuracy and flexibility at the expense of simplicity and user friendliness. The Barlat 1989 and Hill 1990 form a balance between user-friendliness and accuracy, with Barlat 1989 having an edge over Hill 1990 seeing its quality index.

\section{References}

1. Banbic D. Sheet metal forming processes- constitutive modeling and numerical simulation; 2010.

2. Hill R. A theory of the yielding and plastic flow of anisotropic metals. Proceedings of the Royal Society London A. 1948; 193(1033):281-97.

3. Hill R. Constitutive modeling of orthotropic plasticity in sheet metals. Journal of the Mechanics and Physics of Solids. 1990; 38(3):405-17.

4. Barlat F, Brem JC, Yoon JW, Chung K, Dick RE, Choi SH, Pourboghrat F, Chu E, Lege DJ. Plane stress yield function for aluminium alloy sheets - Part 1: Theory. International Journal of Plasticity. 2003; 19(9):297-319.

5. Barlat F. Constitutive modeling for aluminium sheet forming simulations. In: Khan AS, Zhang H, Yuan Y, editors, Plastic and viscoplastic response of materials and metal forming. Proceedings of the 8th International Symposium in Plasticity and its Current Applications, Whistley, Canada, Neat Press: Fulton, MD; 2000. p. 591-3.

6. Barlat F, Richmond O. Prediction of tricomponent plane stress yield surfaces and associated flow and failure behavior of strongly textured FCC polycrystalline sheets. Materials Science and Engineering. 1987; 91:15-29.

7. Banabic D, Cazacu O, Barlat F, Comsa DS, Wagner S, Siegert K. Recent anisotropic yield criteria for sheet metals. Proceedings of the Romanian Academy. 2002; 3(3):91-9.

8. Paraianu L. Modelling of the FLC using the large deformation theory. PhD Thesis, Cluj Napoca, Romania (in Romanian); 2006. p. 1-18.

9. Zhang S, Leotoing L, Guines D, Thuillier S. Calibration of material parameters of anisotropic yield criterion with conventional tests and biaxial test. Key Engineering Materials; 2013. p. 554-7.

10. Meuwissen MHH. Yield criteria for anisotropic elastoplastic metals. Eindhoven : Technische Universiteit Eindhoven; 1995. p. 1-23. 
11. Banabic D, Balan T, Comsa DS. A new yield criterion for orthotropic sheet metals under plane-stress conditions. Proceedings of the 7th Conference 'TPRCluj Napoca, Romania; 2000. p. 217-24.

12. Paraianu L, Banabic D. Predictive accuracy of different yield criteria. Proceedings of the SISOM Conference, Bucharest; 2006. p. 465-574.

13. Gyu-Sei Yi. Anisotropic constitutive model for predictive analysis of composite laminates. Indian Journal of Science and Technology. 2015; 8(S1):189-93.

14. Kotkunde NA, Aditya D, Deole A, Gupta AK, Singh SK. Experimental and numerical investigation of anisotropic yield criteria for warm deep drawing of Ti-6Al-4V alloy. Materials \& Design. 2014; 63:336-44.

15. Janbakhsh M, Loghmanian SMR, Djavanroodi F. Application of different hill's yield criteria to predict limit strains for aerospace titanium and aluminum sheet alloys. International Journal of Advanced Design and Manufacturing Technology. 2012; 7(1):1-10.

16. Çoğun F. Implementation and comparison of different constitutive models in deep drawing process, a thesis submitted to the graduate school of natural and applied sciences of Middle East technical university; 2013. p. 1-103.

17. Banabic D, Wagner S. Anisotropic behavior of aluminium alloy sheets. Aluminium. 2002; 78:926-30.
18. Barlat F, Banabic D, Cazacu O. Anisotropy in sheet metals. In: Yang D-Y, Oh SI, Huh H, Kim YH, editors, Design innovation through virtual manufacturing. Proceedings of the NUMISHEET Conference, Jeju Island, Korea; 2002. p. 515-24.

19. S.P. Sundar Singh Sivam, M.Gopal , Dr. S.Venkatasamy, Mr. Siddhartha Singh. An Experimental Investigation And Optimisation Of Ecological Machining Parameters On Aluminium 6063 In Its Annealed And UnannealedForm. Journal Of Chemical And Pharmaceutical Sciences. p. 46 - 53.

20. Cosovici GA. Implementation of the new yield criteria in the FE programs for sheet metal forming simulation. PhD Thesis, Cluj Napoca, Romania (in Romanian). 2006; 22:174-93.

21. S.P. Sundar Singh Sivam, Umasekar VG, Mishra S, Mishra A, Mondal A. Orbital cold forming technology - combining high quality forming with cost effectiveness - A review. Indian Journal of Science and Technology. 2016 Oct; 9(38). DOI: 10.17485/ijst/2016/v9i38/91426.

22. S.P. Sundar Singh Sivam, Gopal M, Venkatasamy S, Singh S. Application of forming limit diagram and yield surface diagram to study anisotropic mechanical properties of annealed and unannealed SPRC 440E steels. Journal of Chemical and Pharmaceutical Sciences. 2015:15-22. 